\title{
Editorial: The Ecology, Evolution, and Preservation of Biodiversity in Amazonian Floodplain Ecosystems
}

\author{
Lawrence E. Hurd $^{1 *}$, Fabricio B. Baccaro ${ }^{2}$, Marc Pouilly ${ }^{3}$ and Carlos E. C. Freitas ${ }^{4}$ \\ ${ }^{1}$ Department of Biology, Washington and Lee University, Lexington, VA, United States, ${ }^{2}$ Departamento de Biologia, Federal \\ University of Amazonas, Manaus, Brazil, ${ }^{3}$ Laboratoire de Biologie des organismes et des écosystèmes aquatiques, Institut \\ de Recherche pour le Développement, Marseille, France, ${ }^{4}$ Departamento de Ciências Pesqueiras, Federal University of \\ Amazonas, Manaus, Brazil
}

Keywords: Amazon floodplains, tropical biodiversity, flood pulse, invasive species, fisheries management, fish sensory systems, population genetic structure, tropical fish ecology

\section{OPEN ACCESS}

Edited by:

Daniel de Paiva Silva

Goiano Federal Institute

(IFGOIANO), Brazil

Reviewed by:

Dilermando Lima-Junior

Federal University of Mato

Grosso, Brazl

*Correspondence:

Lawrence E. Hurd

hurd@@wlu.edu

Specialty section:

This article was submitted to Biogeography and Macroecology,

a section of the journal

Frontiers in Ecology and Evolution

Received: 13 October 2021

Accepted: 28 October 2021

Published: 25 November 2021

Citation:

Hurd LE, Baccaro FB, Pouilly $M$ and

Freitas CEC (2021) Editorial: The

Ecology, Evolution, and Preservation

of Biodiversity in Amazonian

Floodplain Ecosystems.

Front. Ecol. Evol. 9:794472.

doi: 10.3389/fevo.2021.794472
Editorial on the Research Topic

The Ecology, Evolution, and Preservation of Biodiversity in Amazonian Floodplain Ecosystems

\section{INTRODUCTION}

We present this series of papers as a small sample of the diversity of research efforts in Amazon River Basin floodplains. We had hoped to include many more from scientists who originally expressed interest in contributing, but the global pandemic interfered with this, as with so many other human activities. However, we are optimistic that the important work of ecologists, evolutionary biologists, and conservationists continues vigorously in this incredibly diverse and interesting biome.

\section{REGIONAL PELAGIC FISH DIVERSITY IN FLOODPLAIN LAKES}

The Central Amazon River Basin is a huge and complex system, consisting of two principal, environmentally distinct river systems, namely, blackwater and whitewater. Most previous studies of fish diversity here have been of one or a few lakes, usually limited to either blackwater or whitewater systems. Siqueira-Souza et al., for the first time, analyzed a regional database composed of pelagic fish samplings made by independent researchers using a common sampling regime in multiple lakes of both the Rios Negro (blackwater) and Solimões (whitewater). The lakes of these river systems yielded nearly identical total species richness (165 in whitewater and 168 in blackwater), but about $40 \%$ of the species in each system were unique, which boosted regional richness higher than if lakes from only one of these systems were sampled. In addition, there were differences in species richness among lakes of the same system ( $\beta$ diversity), especially in blackwater. These findings have implications for designing protected areas to preserve aquatic biodiversity. 


\section{FLOODPLAIN TREE SPECIES RESPOND TO THE FLOOD PULSE}

The annual flood pulse is known to be a principal driver of ecological community structure and ecosystem functioning in floodplains of the Amazon Basin. Householder et al. examined models that relates the structure of tree species assemblages on floodplains of the Rio Negro to flood duration in an attempt to discern flood tolerance ranges as a niche property of 111 of the most common tree species in that river basin. They corroborated the hypothesis that flood duration is an important driver of species turnover in floodplain forests, but not the only one: there remain unexplained niche factors that determine variation among the 41 sites included in their study, which require further investigation. The median flood duration tolerance (niche breadth) was found to be 85 days/year, but $27 \%$ of species were not responsive to flood duration. Nevertheless, the flood tolerance response models confirm the importance of this factor to floodplain tree ecology.

\section{SINGLE-SPECIES CO-MANAGEMENT IMPROVES FISH ASSEMBLAGES}

The influence of abiotic and biotic factors structuring fish assemblages of freshwater systems has often been documented. The effects of anthropogenic actions, increasingly at the forefront of fish ecology, have been mainly disruptive. Medeiros-Leal et al. reported the positive effects of a strategy of co-management developed toward protecting one target species (in this case, Arapaima sp., an important food fish) as a stand-in for a larger assemblage of co-occurring species. The co-management initiative is achieved by zoning a lake system, establishing lakes with different levels of restriction, including no-fishing lakes. Based on their results, the authors hypothesized that no-fishing lakes encourage colonization by new species, and provide a positive spillover effect to all lakes in the system regardless of zoning.

\section{FISH SENSORY SYSTEMS AND BIODIVERSITY}

Although the Amazon River Basin harbors the highest freshwater fish diversity in the world, and several hypotheses have been proposed to explain this, most of them lack a specific mechanism for diversification on this scale. The review paper by Borghezan et al. focuses on the interaction between fish sensory systems (photo, mechano, chemo, and electro-reception) and the limnological differences among different water types in this highly heterogeneous ecosystem ( $\mathrm{pH}$, nutrient load, electrical conductivity, and light). The sensory drive hypothesis presented in this review focuses on how sensory or communication systems can adapt to local environmental conditions. Such local adaptations can drive divergences in communication systems, fostering speciation among populations living in contrasting environments. The sensory drive hypothesis thereby provides explicit mechanisms that help explain the current fish diversity in the Amazon Basin.

\section{GENETIC STRUCTURE IN THE PALM EUTERPE PRECATORIA}

The palm family Arecaceae contains a very large and geographically diverse group of tropical and subtropical trees, many of which are economically important. Ramos et al. report on a first study of the genetic structure and diversity of Euterpe precatoria, native to the western and central Brazilian Amazon. This species is valued as a source of immensely popular edible fruit, açaí, which is delicious and contains antioxidants and other desirable properties. Current extractive methodology (cutting the plants) is not sustainable, leading to reduced natural regeneration. Adequate management practices will require monitoring genetic diversity of natural populations in order to maintain genetic viability in the long run. The data from extracted DNA in natural populations of the palm revealed high genetic diversity, critical information for domestication of the species. Gene flow among geographically separate populations is negatively related to distance between them, creating genetic isolation among incipient subpopulations that contributes to regional genetic diversity. This should help guide sustainable agromanagement design and implementation for E. precatoria, and other extractable plants in the future.

\section{THE THREAT OF NON-NATIVE FISH IN THE AMAZON}

Among the many anthropogenic threats to the Amazon River Basin, the introduction of non-native fish (NNF) has been among the least well-documented to date. The paper by Doria et al. is an attempt to shed better light onto the potential and actual impacts of invasive species on native biodiversity in this particular region, which increasingly is also a global problem in a wide variety of ecosystems. Data from six countries within the Basin, covering $80 \%$ of this area, revealed 41 species of fish that were introduced to Amazonian ecosystems, more than half of which were either part of the aquarium trade or involved in aquaculture as a food source. The authors point out that NNFs are still relatively few, compared with other South American countries, so the threat has been "silent" until now. Therefore, we must work to create efficacious strategies to manage or eliminate NNFs before their effects on native biodiversity get rapidly worse.

\section{AUTHOR CONTRIBUTIONS}

All authors listed have made a substantial, direct, and intellectual contribution to the work and approved it for publication. 


\section{ACKNOWLEDGMENTS}

We are grateful for the Editorial assistance of Roksana Majewska and Jasmine Lee, and also for the careful judgement of our many reviewers.

Conflict of Interest: The authors declare that the research was conducted in the absence of any commercial or financial relationships that could be construed as a potential conflict of interest.

Publisher's Note: All claims expressed in this article are solely those of the authors and do not necessarily represent those of their affiliated organizations, or those of the publisher, the editors and the reviewers Any product that may be evaluated in this article, or claim that may be made by its manufacturer, is not guaranteed or endorsed by the publisher.

Copyright $\odot 2021$ Hurd, Baccaro, Pouilly and Freitas. This is an open-access article distributed under the terms of the Creative Commons Attribution License (CC BY). The use, distribution or reproduction in other forums is permitted, provided the original author(s) and the copyright owner(s) are credited and that the original publication in this journal is cited, in accordance with accepted academic practice. No use, distribution or reproduction is permitted which does not comply with these terms. 